\title{
Variable Phenotype in a P102L Gerstmann-Sträussler-Scheinker Italian Family
}

\author{
Giuseppe De Michele, Maurizio Pocchiari, Rossella Petraroli, Mario Manfredi, \\ Giorgio Caneve, Giovanni Coppola, Carlo Casali, Francesco Saccà, \\ Pedro Piccardo, Elena Salvatore, Alfredo Berardelli, Marcello Orio, \\ Fabrizio Barbieri, Bernardino Ghetti, Alessandro Filla
}

\begin{abstract}
Background: Gerstmann-Sträussler-Scheinker disease is an autosomal dominant prion disease. The clinical features include ataxia, dementia, spastic paraparesis and extrapyramidal signs. Methods: We report a new large Italian family affected by Gerstmann-Sträussler-Scheinker disease. Results: The four generation pedigree includes 11 patients. The mean age at onset \pm SD was $41.4 \pm 16.2$ years. Mean disease duration to death in four patients was $5.5 \pm 1.7$ years. Two clinical patterns were evident: cognitive impairment with scarce neurological features or ataxia followed by cognitive impairment. Molecular analysis showed P102L mutation in PRNP gene. Conclusion: Three Italian families have been reported to date. The variable phenotype has already been reported, and does not appear related to the codon 129 polymorphism.
\end{abstract}

\begin{abstract}
RÉSUMÉ: Phénotype variable dans une famille italienne atteinte de la maladie de Gerstmann-SträusslerScheinker due à une mutation P102L. Introduction: La maladie de Gerstmann-Strâussler-Scheinker est une maladie à prion à transmission autosomique dominante. Les manifestations cliniques de la maladie sont de l'ataxie, une démence, une paraparésie spastique et des signes extrapyramidaux. Méthodes: Nous décrivons une grande famille italienne atteinte de maladie de Gerstmann-Sträussler-Scheinker, jamais rapportée antérieurement. Résultats: L'arbre généalogique comprend 11 patients répartis sur 4 générations. L'âge de début moyen était de 41,4 \pm 16,2 ans. La durée moyenne de la maladie jusqu'au décès chez quatre patients était de $6,2 \pm 1,9$ ans. Deux tableaux cliniques étaient évidents: détérioration cognitive avec peu de manifestations neurologiques ou ataxie suivie de détérioration cognitive. L'analyse moléculaire a montré la présence de la mutation P102L dans le gène PRNP. Conclusions: Trois familles italiennes ont été rapportées jusqu'à maintenant. La variabilité du phénotype a déjà été rapportée et ne semble pas en relation avec le polymorphisme du codon 129.
\end{abstract}

Can. J. Neurol. Sci. 2003; 30: 233-236

Gerstmann-Sträussler-Scheinker (GSS) disease is an autosomal dominant prion disease, pathologically characterized by widespread amyloid plaque formation. The most frequent mutation is at codon 102 of the prion protein gene (PRNP), but other point mutations have been found. ${ }^{1,2}$ Onset is usually in the fourth-fifth decade and disease duration varies from two to 10 years. Clinically, GSS is characterized by progressive cerebellar ataxia, associated with other clinical signs, such as dementia, myoclonus and spinal cord tract involvement, which occur frequently, but not invariably, and often late during the clinical course of the disease. In its various genetic forms, GSS can present as a predominantly ataxic syndrome, a spastic paraparesis, an extrapyramidal syndrome, a presenile dementia, and a Creutzfeldt-Jakob disease. ${ }^{1,3}$ We report a new large Italian family affected by GSS associated with P102L mutation.

\section{FAMILY REPORT}

The four-generation pedigree includes 11 patients (Figure 1). Four patients were personally observed by the authors (AF, MM, GC) and the clinical file was available in another (Table). The

From the Department of Neurological Sciences, Federico II University, Naples (GDM, GC, FS, ES, MO, FB, AF); Laboratory of Virology, Istituto Superiore di Sanità, Rome (MP, RP); Department of Neurological Sciences, La Sapienza University, Rome (MM, $\mathrm{CC}, \mathrm{AB})$; Neuromed Institute, Isernia (MM, AB); Neurology Section, Feltre Hospital, Belluno (GC); Department of Pathology and Laboratory Medicine, Indiana University School of Medicine, Indianapolis, USA (PP, BG)

ReCeived DeCEMber 02, 2002. ACCEPTED IN Final form March 13, 2003. Reprint requests to: Alessandro Filla, Dipartimento di Scienze Neurologiche, Università degli Studi di Napoli Federico II, Via Pansini 5, I-80131, Napoli, Italy. E-mail: afilla@unina.it 


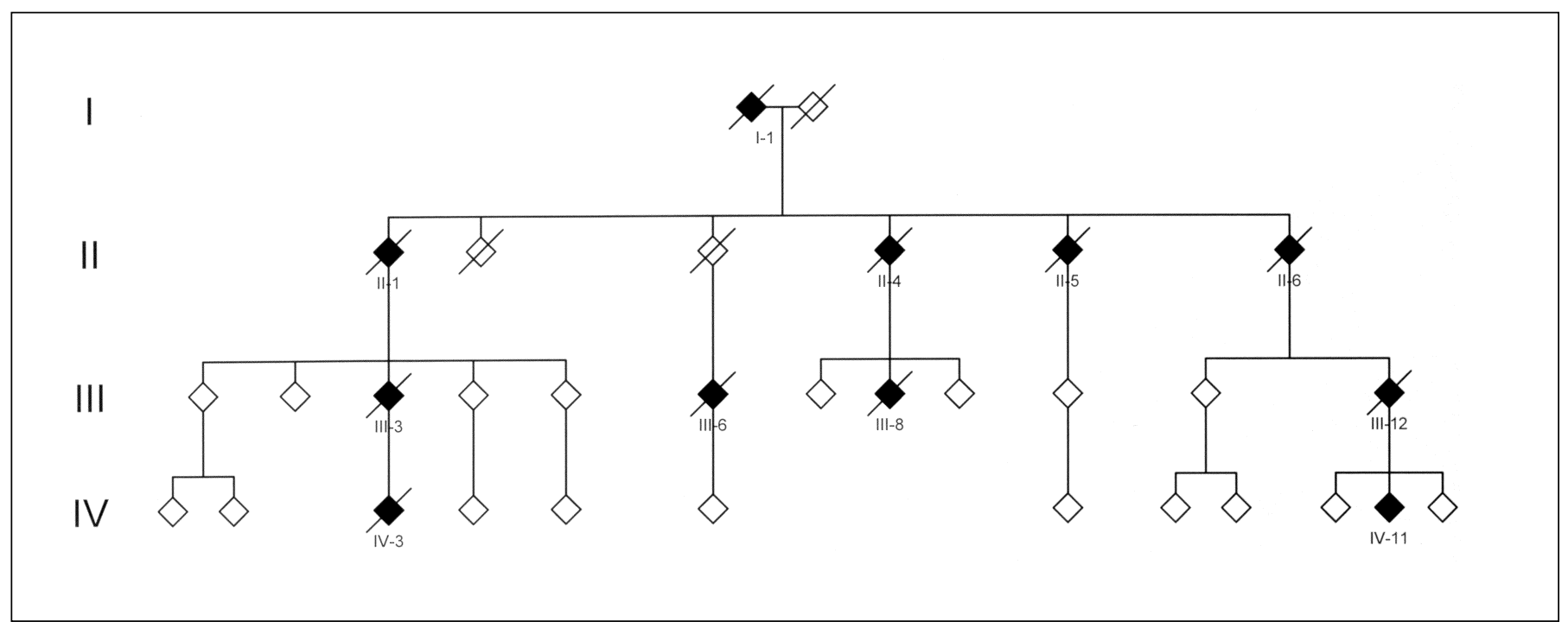

Figure 1: Family pedigree.

mean age at onset \pm SD was $41.4 \pm 18.1$ (22-71) years. Mean disease duration to death in four patients was $5.5 \pm 1.7$ (3-7) years.

Two clinical patterns were evident: cognitive impairment with scarce neurological features or ataxia followed by cognitive impairment. Patients III-12 and IV-11 are reported in more details and are examples of the different clinical patterns.

Patient III-12 had onset at 38 years, complaining of lower limb dysesthesias, unsteadiness, falls and urinary urgency. The neurological examination, at the age of 40 years, showed ataxic gait, nystagmus in lateral gaze, jerky smooth pursuit, dysmetric saccades, hyponasal and slurred speech, dysphagia, marked dysmetria at heel-to-knee, absent knee and ankle jerks, decreased

Table: Clinical and laboratory data in five patients

\begin{tabular}{llllll}
\hline & III-3 & III-8 & III-12 & IV-3 & IV-11 \\
Sex & F & M & F & M & F \\
Age at onset & 41 & 71 & 38 & 35 & 22 \\
Onset sign & Ataxia & Falls & Ataxia & Dementia & Dementia \\
Disease duration & 6 & 6 & 7 & 3 & 9 \\
Age at death & 47 & 77 & 45 & 38 & \\
Gait ataxia & +++ & +++ & +++ & - & - \\
Dysarthria & + & - & +++ & - & - \\
Dysmetria & + & - & +++ & - & - \\
Nystagmus & + & + & + & - & - \\
Knee jerks & - & - & - & ++ & ++ \\
Babinski signs & + & - & + & - & - \\
Dementia & + & ++ & +++ & ++ & ++ \\
MRI/CT & $\mathrm{NP}$ & $\mathrm{A}$ & $\mathrm{A}$ & $\mathrm{A}$ & $\mathrm{A}$ \\
EEG & $\mathrm{N}$ & $\mathrm{N}$ & $\mathrm{N}$ & $\mathrm{A}$ & $\mathrm{A}$ \\
& & & & &
\end{tabular}

- = absent; + to +++ = presence and degree; $\mathrm{N}=$ normal; $\mathrm{A}=$ abnormal; NP: not performed. tone and Babinski signs. The patient was markedly depressed. The CT scan showed cerebellar atrophy, and VEP increased P1 latency. At the last examination, at the age of 43 years, she was unable to walk, hypotonic, and areflexic. Dementia, pseudobulbar affect, and urinary incontinence were present. She died of pneumonia at the age of 45 years.

Patient IV-11 (child of III-12) used to be a bright student. Onset was at about 22 years with decreased study performances and difficulties in the correct use of objects. When first observed, at the age of 25 years, she was disoriented in time and space and apraxic. Verbal fluency, memory and calculation were severely impaired. The neurological examination showed normal extraocular motility; brisk knee jerks; flexor plantar response; normal gait, coordination and vibration sense. Magnetic resonance imaging showed cerebral and cerebellar atrophy (Figure 2); EEG showed diffuse slowing with spikes in left temporal leads; 99mTC-HMPAO SPET showed temporo-parietal decreased perfusion; neuropsychological examination marked deterioration of the cognitive functions. Neurophysiological evaluation showed increased P1 latency with normal amplitude and delayed central motor conduction time. At the last examination, at the age of 31 years, gait and stance were normal; she was unable to speak and completely dependent for feeding and personal hygiene. She also presented with insomnia, agitation and loss of weight.

Patient III-3 (file) started with ataxia at the age of 41 years, and received a diagnosis of multiple sclerosis. A pneumoencephalography showed enlargement of the third and fourth ventricles, pontine cisterns, and temporal horns of lateral ventricles. She died of aspiration pneumonia after six years.

Patient III-8 had an onset with frequent falls at the age of 71 years, and received a diagnosis of progressive supranuclear palsy. Ataxia followed and, in later stages, he was bedridden with severe dementia, muteness and aggressiveness. A CT scan performed in early stages of the disease showed cortical atrophy. He died at 77 of pneumonia.

Patient IV-3 (child of III-3) showed withdrawal behaviour, 

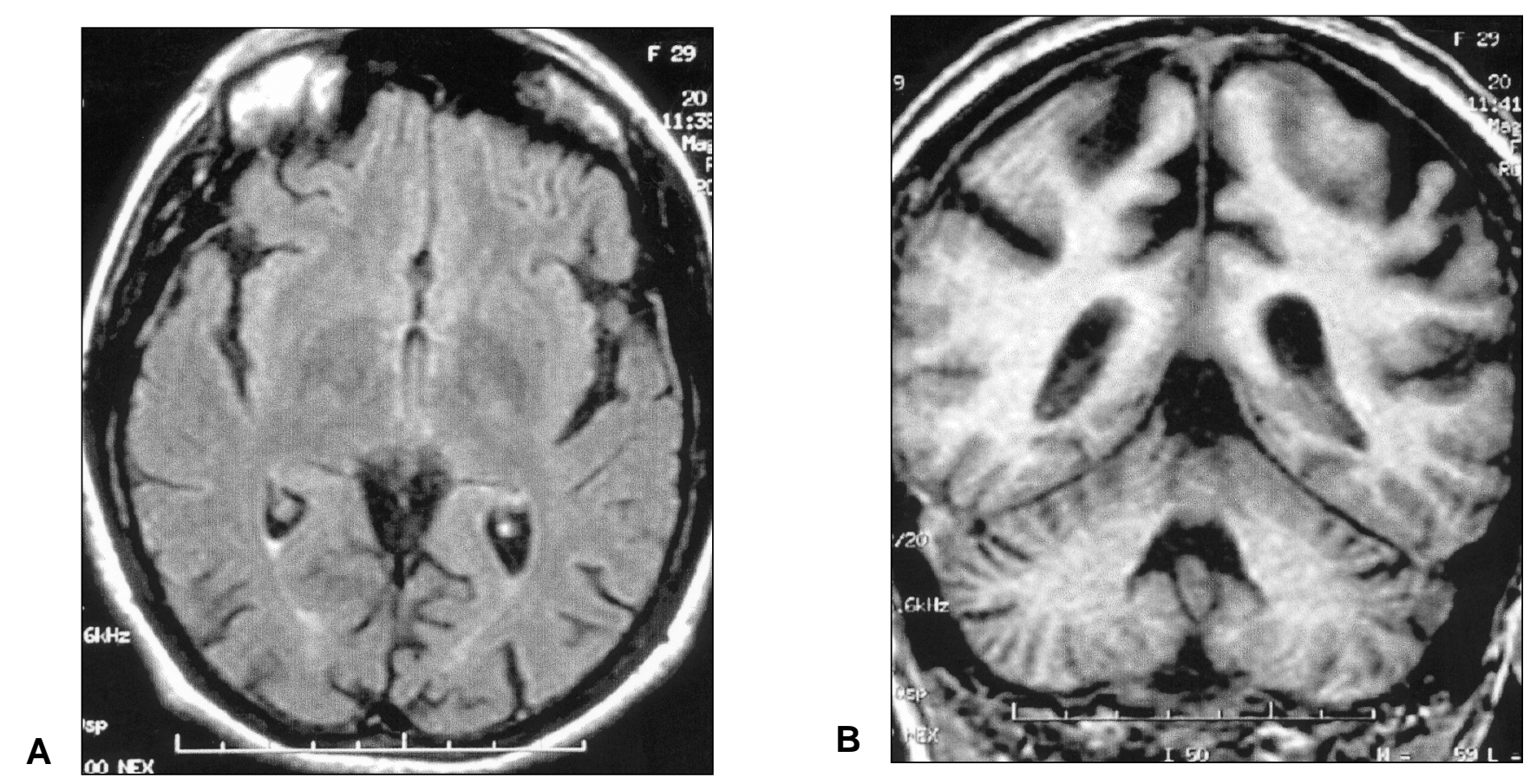

Figure 2: Axial (a) and coronal (b) MRI sections showing brain atrophy, more marked in the fronto-temporal lobes (patient IV-11, at the age of 29 years).

flattening of affect and loss of volition at the age of 35 years, which led to the diagnosis of hebephrenic schizophrenia. Dementia was subsequently diagnosed on the basis of memory disturbances, marked apraxia, and decreased speech output. Neuropsychological examination could not be performed. Magnetic resonance imaging showed cerebral and cerebellar atrophy; EEG spikes in the temporal leads. He died of pneumonia after a three-year disease duration. The postmortem examination was carried out several years ago. There were only histological slides of the cerebellar cortex stained with hematoxylin-eosin available. A decreased number of Purkinje cells and unicentric kuru-type eosinophilic plaques in the molecular layer were observed in absence of spongiform changes (Figure 3). No tissue for immunohistochemistry was available.

Clinical files were not available for the other six patients. Deaths after a short lasting disabling disease were reported in all. Patients II-1, II-4, II-5 and II-6 were reported to be ataxic and to have died in their 30 s or 40 s.

Patients III-8 and IV-11 gave informed consent for molecular analysis. Sequencing of the $P R N P$ open reading frame showed a $\mathrm{T}$ to $\mathrm{C}$ transition, resulting into a substitution of leucine for proline at residue 102 of the prion protein (P102L). ${ }^{4}$ Patient III8 was homozygous for methionine and IV-11 heterozygous for valine/methionine polymorphism on codon 129 .

Three Italian families have been reported to date. ${ }^{4-6}$ All the families originated from Sicily and shared the same mutation (P102L). The patients from the present family are spread in different districts of Italy. Patient I-1 lived in northeastern Italy, but his family name is common in Sicily. A haplotype study on members of the four families may clarify if a founder-effect occurred. The phenotype varies from that characterized by ataxia and areflexia, followed by dementia, to that characterized by early cognitive impairment. The variable phenotype has already been reported ${ }^{4,7}$ and does not appear related to the codon 129 polymorphism. ${ }^{4}$

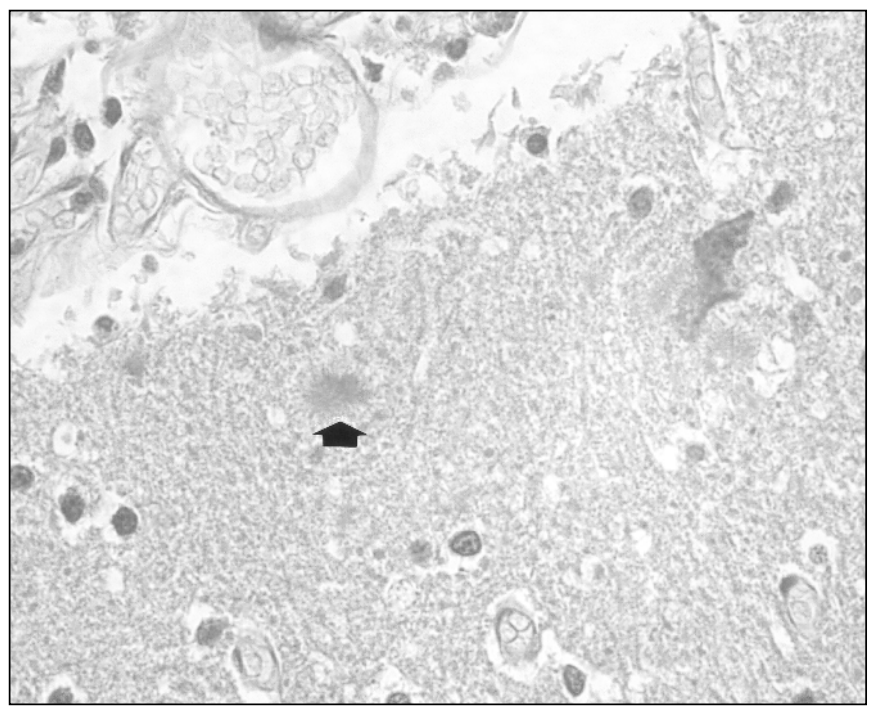

Figure 3: Unicentric kuru-type eosinophilic plaques in the cerebellar molecular layer (patient IV-3). 


\section{ACKNOWLEDGEMENTS}

This work has been partially supported by grants to AF from Italian Ministry of University FIRB, and Ministry of Health.

\section{REFERENCES}

1. Ghetti B, Dlouhy SR, Giaccone G, et al. Gerstmann-SträusslerScheinker disease and the Indiana kindred. Brain Pathol 1995; 5: 61-75.

2. Online Mendelian Inheritance in Man, OMIM (TM). Johns Hopkins University, Baltimore, MD. MIM Number: $\{176640\}:\{3 / 5 / 2002\}$. World Wide Web URL: http://www.ncbi.nlm.nih.gov/omim/

3. Majtenyi C, Brown P, Cervenakova L, Goldfarb LG, Tateishi J. A three-sister sibship of Gerstmann-Sträussler-Scheinker disease with a CJD phenotype. Neurology 2000; 54: 2133-2137.
4. Barbanti P, Fabbrini G, Salvatore M, et al. Polymorphysm at codon 129 or codon 219 of $P R N P$ and clinical heterogeneity in a previously unreported family with Gerstmann-SträusslerScheinker disease (PrP-P102L mutation). Neurology 1996; 47: 734-741.

5. Kretzschmar HA, Kufer P, Riethmüller G, et al. Prion protein mutation at codon 102 in an Italian family with GerstmannSträussler-Scheinker syndrome. Neurology 1992; 42: 809-810.

6. Young $\mathrm{K}$, Jones $\mathrm{CK}$, Piccardo $\mathrm{P}$, et al. Gerstmann-SträusslerScheinker disease with mutation at codon 102 and methionine at codon 129 of $P R N P$ in previously unreported patients. Neurology 1995; 45: 1127-1134.

7. Tanaka Y, Minematsu K, Moriyasu H, et al. A Japanese family with a variant of Gerstmann-Sträussler-Scheinker disease. J Neurol Neurosurg Psychiatry 1997; 62: 454-457. 